\title{
Potencial de redução de exploração de recursos hídricos pelo aproveitamento de água pluvial em residências do Distrito Federal
}

\author{
CÁCERES, Patrícia Silva ${ }^{1}$ \\ RAMOS, Samyrian dos Reis ${ }^{2}$ \\ SANT'ANA, Daniel ${ }^{3}$ \\ ${ }^{1}$ Agência de Águas, Energia e Saneamento Básico do Distrito Federal, Brasília, Brasil. patricia.caceres@adasa.df.gov.br \\ ${ }^{2}$ Agência de Águas, Energia e Saneamento Básico do Distrito Federal, Brasília, Brasil. samyrian.ramos@adasa.df.gov.br \\ ${ }^{3}$ Grupo Água \& Ambiente Construído, Universidade de Brasília, Brasília, Brasil. dsantana@unb.br
}

\begin{abstract}
Resumo
O Distrito Federal situa-se em uma área de vulnerabilidade hídrica. Recentemente enfrentou um período de racionamento em virtude da baixa disponibilidade observada nos mananciais de abastecimento público da região. Tal situação tem motivado a busca de novas fontes hídricas, sendo necessários mananciais cada vez mais distantes e uma crescente complexidade da infraestrutura hídrica para o atendimento destas demandas (gestão da oferta). Entretanto, novas abordagens (gestão da demanda) que priorizem ações de conservação, consumo eficiente e utilização de fontes alternativas de água em edificações devem ser requeridas como opção complementar, não única, à exploração de novos mananciais ou aumento da pressão sobre os já utilizados. Nesse sentido, este artigo busca avaliar o potencial de redução da exploração dos recursos hídricos locais pelo aproveitamento da água pluvial nas edificações, através da comparação do balanço hídrico do principal reservatório de abastecimento da região - Descoberto - no ano crítico de 2016, com outras simulações, considerando premissas pré-determinadas de implantação destes sistemas em larga escala nas edificações localizadas nas Regiões Administrativas abastecidas por esse reservatório. $O$ resultado aponta a forte necessidade de incentivos fiscais e econômicos para que haja, de fato, o aumento da autonomia e da resiliência hídrica no DF pelo aproveitamento da água pluvial.
\end{abstract}

Palavras-Chave: Exploração de Recursos Hídricos, Edificações Residenciais, Aproveitamento de Água Pluvial, Incentivos.

\begin{abstract}
The Federal District is located in an area of water vulnerability. Recently it faced a period of rationing due to the low availability observed in the sources of public supply of the region. This situation has motivated the search for new water sources, requiring increasingly distant sources and increasing complexity of the water infrastructure to meet these demands (supply management). However, new approaches (management of demand) that prioritize actions of conservation, efficient consumption and use of alternative sources of water in buildings should be required as a complementary, not unique option, to the exploration of new sources or increase the pressure on those already used. In this sense, this article seeks to evaluate the potential of reducing the exploitation of local water resources by the use of rainwater in buildings, by comparing the water balance of the main supply reservoir of the region - Descoberto - in the critical year of 2016, with other simulations considering pre-determined premises of implantation of these systems in large scale in the buildings located in the Administrative Regions supplied by this reservoir. The result points to the strong need for fiscal and economic incentives to increase autonomy and water resilience in the Federal District through the use of rainwater.
\end{abstract}

Key-Words: Exploration of Water Resources, Residential Dwellings, Rainwater Harvesting, Incentives. 


\section{Introdução}

Do ponto de vista da oferta de água, o diagnóstico do país consolidado em 2010 já indicava que 46\% das cidades brasileiras apresentavam vulnerabilidades associadas à produção de água e que, dentre estas, 9\% necessitavam de novas fontes hídricas, incluindo o Distrito Federal - DF (ANA, 2017). Desta forma, a combinação de chuvas abaixo da média, altas temperaturas, captações clandestinas, ocupação desordenada, aumento da população - na ordem de 60 mil por ano em média, segundo o IBGE - e ausência de obras estruturantes por mais de 16 anos impactaram diretamente o abastecimento de água em Brasília em 2017 e 2018 (até meados de junho), principalmente a população abastecida pelos reservatórios do Descoberto e Santa Maria (ANA, 2017).

A baixa disponibilidade hídrica observada no DF contrasta com a crescente pressão sobre os seus mananciais. Tal fato tem motivado a busca de novas fontes hídricas, sendo necessários mananciais cada vez mais distantes e uma crescente complexidade da infraestrutura hídrica para o atendimento destas demandas: gestão da oferta (ANA, 2017).

Com isso, novas abordagens que priorizem ações de conservação, consumo eficiente e utilização de fontes alternativas de água em edificações devem ser requeridas como opção complementar, não única, à exploração de novos mananciais ou ao aumento da pressão sobre os já utilizados (ABNT, 2018). Esta é uma abordagem voltada à gestão da demanda, sendo uma questão emergencial em centros urbanos com vulnerabilidade hídrica no Brasil, independente de eventual falta de chuva em determinada época ou região (CBCS, 2014).

Atentos a esta situação, a Agência Reguladora de Águas, Energia e Saneamento Básico do Distrito Federal - Adasa em parceria com a Universidade de Brasília - UnB firmaram convênio em março de 2016, com o objetivo de analisar a viabilidade técnica, econômica e ambiental de fontes alternativas de água não potável em edificações (onde o aproveitamento da água pluvial - AAP se insere) para orientar uma tomada de decisão baseada em análises de custo-benefício.

Diante dos resultados apresentados na primeira etapa da pesquisa - edificações residenciais - ocorreu uma consulta pública no site da agência por aproximadamente 45 dias (encerramento em 30 de agosto), a qual apresentou o texto da minuta da resolução que "estabelece diretrizes para implantação e operação de sistemas prediais de água não potável em edificações residenciais" - AUDIÊNCIA PÚBLICA No 06/2018, com o objetivo de obter subsídios e informações adicionais para o aprimoramento do documento (ADASA, 2018). Em 15 de agosto foi realizada audiência pública presencial em sua sede. E, em 20 de março de 2019 foi enfim publicada a Resolução Adasa n.03: a primeira a tratar sobre esse tema no país.

Diante disto, este artigo foca apenas nas edificações residenciais, tendo em vista que, segundo dados da prestadora - Companhia de Saneamento Ambiental do Distrito Federal, CAESB - de 2016 (PDSB, 2017), a porcentagem das ligações, economias e volume faturado nesta categoria são bastante significativos (conforme Tabela 1 abaixo), justificando a importância da implantação de estratégias conservadoras de água nesse tipo de categoria 
Tabela 1: Participação das categorias em relação ao total de ligações, economias e volume faturado.

\begin{tabular}{llll}
\hline Categoria & Ligações & Economias & Volume Faturado \\
\hline Residencial Normal & $91,05 \%$ & $94,38 \%$ & $82,79 \%$ \\
Residencial Popular & $0,36 \%$ & $0,25 \%$ & $0,17 \%$ \\
Comercial & $8,00 \%$ & $5,00 \%$ & $10,40 \%$ \\
Industrial & $0,17 \%$ & $0,11 \%$ & $0,76 \%$ \\
Público & $0,43 \%$ & $0,27 \%$ & $5,87 \%$ \\
\hline
\end{tabular}

Fonte: CAESB, 2016

Aliado a isso, sistemas prediais de aproveitamento de água pluvial são objeto de lei federal e distritais, com uma destas, inclusive, impondo a obrigatoriedade de implantação em algumas situações, como condição para concessão do habite-se:

- Lei Federal no 13. 501/2017 que "altera o art. $2^{\circ}$ da Lei no 9.433, de 8 de janeiro de 1997, que institui a Política Nacional de Recursos Hídricos, para incluir o aproveitamento de águas pluviais como um de seus objetivos";

- Lei Distrital $n^{\circ}$ 4.181/2008 que cria o "Programa de Captação de Água da Chuva" como condição para concessão do habite-se. Até hoje sem regulamentação pelo Poder Executivo;

- Lei Distrital n $\quad$ 5.890/2017 que "estabelece diretrizes para políticas públicas de reúso da água no Distrito Federal através do uso de água não potável em edificações não industriais no Distrito Federal”. Apesar de constar reúso na ementa da lei, o aproveitamento de água pluvial também foi contemplado;

- Lei Distrital Complementar n 929/2017 que "dispõe sobre dispositivos de captação de águas pluviais para fins de retenção, aproveitamento e recarga artificial de aquíferos em unidades imobiliárias e empreendimentos localizados no Distrito Federal";

- Lei Distrital n 5965/2017 que “dispõe sobre a redução no Imposto Predial e Territorial Urbano - IPTU aos proprietários de imóveis residenciais e não residenciais que adotarem o Aproveitamento de Água Pluvial e/ou o Reúso de Água Cinza, dentre outras medidas." Também sem regulamentação; e

- Lei Distrital n 6065/2018 de 11 de janeiro de 2018 que "institui a política de incentivo ao reaproveitamento da água da chuva". Ressaltando que a água da chuva deve ser aproveitada, uma vez que não passou por outro uso anteriormente, demonstrando um certo desconhecimento por parte do legislador.

Nesse sentido, o objetivo do artigo consiste em avaliar o potencial de redução da exploração dos recursos hídricos locais pelo AAP nas edificações, através da comparação do balanço hídrico do principal reservatório de abastecimento da região - Descoberto - (responsável pelo abastecimento de mais $60 \%$ da população do DF) no ano crítico de 2016, com outras simulações considerando premissas pré-determinadas de implantação destes sistemas em larga escala nas edificações residenciais localizadas nas Regiões Administrativas (RA's) abastecidas por este reservatório. 


\section{Metodologia}

Sant'Ana e Medeiros (2017) estimaram, dentre outras fontes alternativas, as viabilidades técnica, econômica e ambiental de sistemas prediais de aproveitamento de água pluvial (AAP), a partir da composição de 4 (quatro) modelos representativos das principais tipologias residenciais (unifamiliar ou multifamiliar) do DF por faixa de renda (residência renda alta - RRA; residência renda média alta RRMA; residência renda média baixa - RRMB; e residência renda baixa - RRB), sendo um modelo para cada faixa.

Para composição destes modelos representativos foi necessário o levantamento de informações indispensáveis à compreensão dos usos finais da água e à determinação dos indicadores de consumo. Para isso, foram utilizadas técnicas de entrevistas, levantamento documental (contas de água e projetos dos sistemas prediais hidráulicos) e levantamento de campo (para os casos onde não existiam projeto).

Ainda dentro da viabilidade técnica (modelos representativos), foram avaliadas diferentes possibilidades de adaptação predial voltadas ao AAP em casas e apartamentos. Nesta análise, o estudo buscou soluções simples e eficazes, por meio de intervenções pontuais a nível de barrilete ou, no caso de prédios, em shafts da rede de água fria. Neste momento, também foram averiguadas a existência de rede coletora de águas pluviais e possíveis adaptações para o desvio das águas das chuvas captadas pela cobertura para tratamento e armazenagem. As características típicas das instalações hidráulicas foram agregadas aos modelos representativos para também servirem de base na avaliação dos custos e benefícios financeiros (viabilidade econômica) dos diferentes sistemas analisados, através do payback, valor presente líquido e do custo incremental médio.

Quanto à viabilidade ambiental (objeto deste artigo), para a análise do potencial de redução do consumo de água pelo AAP foi necessário primeiramente conhecer a demanda de água total por Região Administrativa (RA) e total no reservatório do Descoberto no ano de 2016, conforme Tabela 2 abaixo. Para isso, Sant'Ana e Medeiros (2017) utilizaram dados da CAESB e da Companhia de Planejamento do Distrito Federal (CODEPLAN).

Tabela 2: Demanda de água por Região Administrativa abastecida pelo reservatório do Descoberto.

\begin{tabular}{|c|c|c|c|c|c|}
\hline \multirow{2}{*}{$\begin{array}{l}\text { Região } \\
\text { Administrativa }\end{array}$} & \multirow{2}{*}{ Faixa de Renda } & \multirow{2}{*}{$\begin{array}{l}\text { Número de } \\
\text { Residências }\end{array}$} & \multirow{2}{*}{$\begin{array}{l}\text { Tipologia } \\
\text { Predominante }\end{array}$} & \multicolumn{2}{|c|}{ Demanda de Água } \\
\hline & & & & (m³/res/ano) & $\left(\times 10^{3} \cdot \mathrm{m}^{3} / \mathrm{ano}\right)$ \\
\hline Gama & RRMB & 41.176 & Unifamiliar & 137 & $5.641,11$ \\
\hline Taguatinga & RRMB & 64.810 & Unifamiliar & 159 & $10.304,8$ \\
\hline Núcleo Bandeirante & RRMB & 7.828 & Multifamiliar & 140 & 1.096 \\
\hline Ceilândia & RRB & 139.395 & Unifamiliar & 118 & $16.448,61$ \\
\hline Guará & RRMB & 46.437 & Multifamiliar & 161 & $7.476,35$ \\
\hline Samambaia & RRB & 69.647 & Unifamiliar & 130 & $9.054,11$ \\
\hline Santa Maria & $\mathrm{RRB}$ & 34.685 & Unifamiliar & 136 & $4.717,16$ \\
\hline Recanto das Emas & $\mathrm{RRB}$ & 41.890 & Unifamiliar & 107 & $4.482,23$ \\
\hline Riacho Fundo I & RRMB & 12.994 & Unifamiliar & 138 & $1.793,17$ \\
\hline Candangolândia & RRMB & 4.801 & Unifamiliar & 148 & 710,54 \\
\hline Águas Claras & RRMA & 48.745 & Multifamiliar & 211 & $10.285,2$ \\
\hline Riacho Fundo II & RRB & 15.032 & Unifamiliar & 139 & $2.089,44$ \\
\hline Park Way & RRA & 5.914 & Unifamiliar & 342 & $2.025,88$ \\
\hline Vicente Pires & RRMA & 20.206 & Unifamiliar & 190 & $3.839,14$ \\
\hline TOTAL & & & & & $79.963,74$ \\
\hline
\end{tabular}

Fonte: Sant'Ana e Medeiros (2017), PDAD (2016), CAESB (2016). 
Posteriormente, foi necessário estimar a economia de água potável pelo emprego dos sistemas prediais de águas pluviais por faixa de renda na escala da edificação (visão micro - Tabela 3 , segundo a viabilidade econômica e ambiental), considerando sempre a melhor tecnologia em termos de economia de água.

Para isso, três tipos diferentes de demandas para estas águas pluviais foram considerados na análise:

- Demanda 1: Irrigação e lavagem de pisos;

- Demanda 2: Irrigação, lavagem de pisos e descarga sanitária;

- Demanda 3: Irrigação, lavagem de pisos, descarga sanitária e lavagem de roupas.

Em seguida, foi possível estimar a economia de água total no reservatório, segundo a viabilidade econômica (visão macro, conforme Tabela 4 abaixo), considerando que 100\% destas residências haviam implantado os sistemas, haja vista que apenas 3 (três) RA's (de melhor poder aquisitivo) apresentaram tal viabilidade, em virtude do ainda elevado custo do investimento.

Tabela 3: Economia de água pelo emprego do AAP por faixa de renda segundo as viabilidades econômica e ambiental

\begin{tabular}{lll}
\hline Faixa de Renda & $\begin{array}{l}\text { Viabilidade Econômica } \\
\text { Demanda - cisterna }-\mathrm{m}^{3} \text { economizado }\end{array}$ & $\begin{array}{l}\text { Viabilidade Ambiental } \\
\text { Demanda - cisterna }-\mathrm{m}^{3} \text { economizado }\end{array}$ \\
\hline RRA & Demanda 3 - cisterna de $50 \mathrm{~m}^{3}-203 \mathrm{~m}^{3}$ & Demanda 3 - cisterna de $80 \mathrm{~m}^{3}-229 \mathrm{~m}^{3}$ \\
RMA & Demanda 1 - cisterna de $25 \mathrm{~m}^{3}-2,4 \mathrm{~m}^{3}$ & Demanda 1- cisterna de $25 \mathrm{~m}^{3}-2,4 \mathrm{~m}^{3}$ \\
RRMB & $\mathrm{NE}^{*}$ (não existe) & Demanda 3 - cisterna de $30 \mathrm{~m}^{3}-122,4 \mathrm{~m}^{3}$ \\
RRB & $\mathrm{NE}^{*}$ (não existe) & Demanda 3 - cisterna de $25 \mathrm{~m}^{3}-95,8 \mathrm{~m}^{3}$
\end{tabular}

Fonte: Sant'Ana e Medeiros (2017) adaptado

Tabela 4: Economia de água segundo a viabilidade econômica

\begin{tabular}{llll}
\hline Região Administrativa & $\mathbf{N}^{\circ}$. Residências & Economia & Viabilidade Econômica \\
\hline Águas Claras & 48745 & $2,4 \mathrm{~m}^{3} / \mathrm{res} / \mathrm{ano}$ & $116.988 \mathrm{~m}^{3} / \mathrm{ano}$ \\
Park Way & 5914 & $203 \mathrm{~m}^{3} / \mathrm{res} / \mathrm{ano}$ & $1.200 .542 \mathrm{~m}^{3} / \mathrm{ano}$ \\
Vicente Pires & 20206 & $2,4 \mathrm{~m}^{3} / \mathrm{res} / \mathrm{ano}$ & $48.494 \mathrm{~m}^{3} / \mathrm{ano}$ \\
\hline Total Descoberto & & $\mathbf{1 . 3 6 6 . 0 2 4} \mathbf{~ m}^{\mathbf{3}} /$ ano \\
\hline \multicolumn{2}{r}{}
\end{tabular}

Com isso, de maneira similar, foi possível estimar a economia de água total no reservatório, segundo a viabilidade ambiental (visão macro, conforme Tabela 5 abaixo), considerando que $10 \%, 20 \%$ e $50 \%$ destas residências haviam implantado os sistemas. Na viabilidade ambiental, ao contrário da econômica, todas as RA's abastecidas pelo reservatório foram contempladas no cálculo do balanço hídrico.

Tabela 5: Economia de água segundo a viabilidade ambiental

\begin{tabular}{llll}
\hline $\begin{array}{l}\text { Região } \\
\text { Administrativa }\end{array}$ & $\begin{array}{l}\mathbf{N}^{\circ} \text {. } \\
\text { Residências }\end{array}$ & $\begin{array}{l}\text { Economia } \\
\left(\mathbf{m}^{3} / \text { res/ano) }\right.\end{array}$ & $\begin{array}{l}\text { Viab.Amb.AAP } \\
\left(\mathbf{m}^{3} / \mathbf{a n o}\right)\end{array}$ \\
\hline Águas Claras & 48.745 & 2,4 & 116.988 \\
Candangolândia & 4.801 & 122,4 & 587.642 \\
Ceilândia & 139.395 & 95,8 & 13.354 .041 \\
Gama & 41.176 & 122,4 & 5.039 .942 \\
Guará & 46.437 & 122,4 & 5.683 .888
\end{tabular}


Em busca de autonomia e resiliência hídrica no Brasil | Paranoá 23

\begin{tabular}{llll} 
Núcleo Bandeirante & 7.828 & 122,4 & 958.147 \\
Park Way & 5.914 & 229 & 1.354 .306 \\
Recanto das Emas & 41.890 & 95,8 & 4.013 .062 \\
Riacho Fundo I & 12.994 & 122,4 & 1.590 .465 \\
Riacho Fundo II & 15.032 & 95,8 & 1.440 .065 \\
Samambaia & 69.647 & 95,8 & 6.672 .182 \\
Santa Maria & 34.685 & 95,8 & 3.322 .823 \\
Taguatinga & 64.810 & 122,4 & 7.932 .744 \\
Vicente Pires & 20.206 & 2,4 & 48.494 \\
\hline Total Descoberto & & & 52.114 .793 \\
\hline 10\% residências & \multicolumn{5}{l}{5.211 .480} \\
$20 \%$ residências & \multicolumn{5}{l}{10.422 .959} \\
$50 \%$ residências & Fonte: Sant'Ana e Medeiros (2017) adaptado.
\end{tabular}

Assim, o total economizado (tabela 4 considerando $100 \%$ das residências e tabela 5 considerando 10 , 20 e $50 \%$ das residências) foi igualmente dividido em 12 (doze) partes iguais para só então poder ser descontado do volume real captado mensal no ano de 2016. Desta forma, foi possível realizar os novos balanços hídricos, a partir destes novos valores de captação. Estas novas simulações foram comparadas com o volume útil final do reservatório em 31 de dezembro de 2016 (balanço hídrico real).

\section{Resultados}

Conforme observado, a viabilidade econômica (payback positivo) apontou que apenas 3 (três) RA's abastecidas pelo reservatório do Descoberto teriam tido condições de implantar tais sistemas. Constatou também que mesmo em uma situação extremamente otimista, onde $100 \%$ das residências situadas nessas regiões tivessem adotado a melhor tecnologia, em termos de economia de água (Demanda 3: cisterna de $50 \mathrm{~m}^{3}$ - RRA; e Demanda 1: cisterna de $25 \mathrm{~m}^{3}$ - RRMA), o potencial de redução seria pífio (apenas $1 \%$ a mais) se comparado com o balanço hídrico real do ano de 2016 , conforme figura 1 abaixo.

Figura 1: Potencial de redução da exploração dos recursos hídricos no reservatório do Descoberto segundo a viabilidade econômica.

Descoberto 2016 - Viabilidade Econômica - AAP

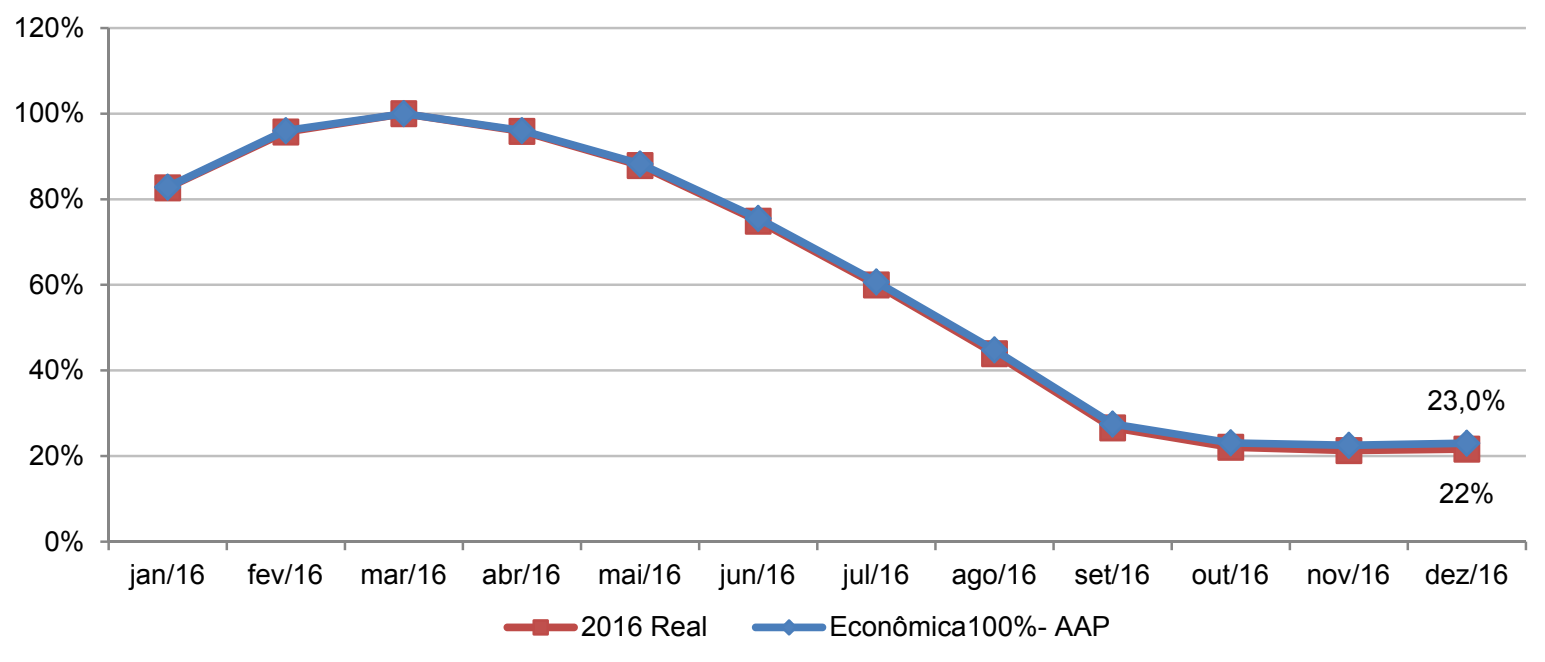


Analisando agora sob a ótica da viabilidade ambiental (payback negativo), todas as 14 (catorze) RA's abastecidas pelo reservatório do Descoberto teriam tido condições de implantar tais sistemas. Deste modo, foi constatado que se $10 \%, 20 \%$ e $50 \%$ das residências situadas nessas regiões tivessem adotado a melhor tecnologia, em termos de economia de água (Demanda 3: cisterna de $80 \mathrm{~m}^{3}$ - RRA;

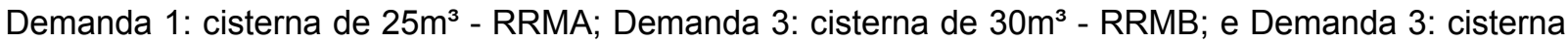
de $25 \mathrm{~m}^{3}$ - RRB), o potencial de redução da exploração dos recursos hídricos locais teria atingido níveis significativos, à medida que mais residências aderissem aos sistemas, conforme figura 2 abaixo.

Figura 2: Potencial de redução da exploração dos recursos hídricos no reservatório do Descoberto segundo a viabilidade ambiental

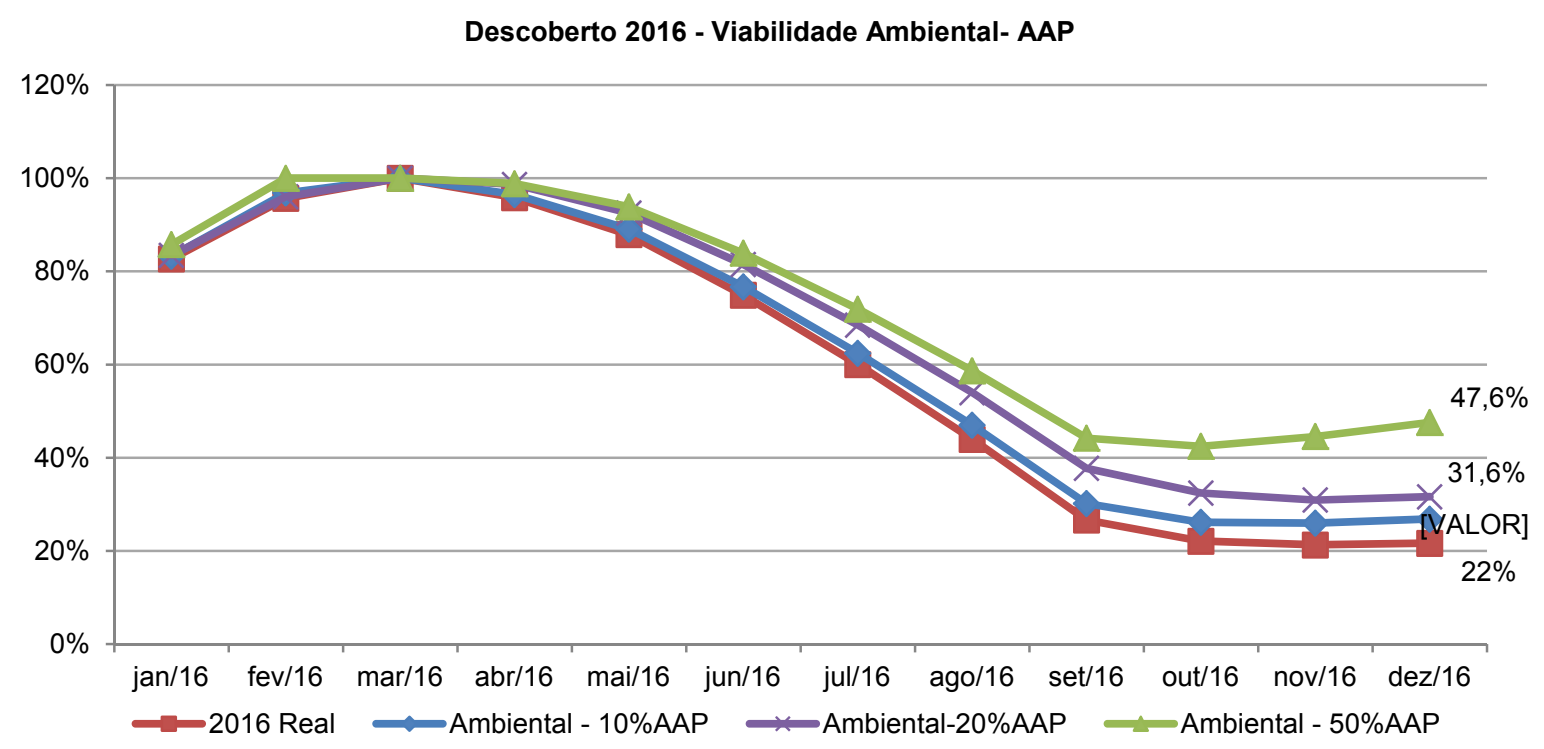

\section{Conclusão}

Em geral, os resultados apontaram que o aproveitamento de águas pluviais em residências pode sim diminuir a demanda por água potável com o uso de uma fonte alternativa confiável em fins não potáveis, diminuindo o nível de exploração do recurso hídrico no DF; promover economia financeira para o usuário; aumentar a disponibilidade hídrica nos reservatórios de abastecimento da região, além de atuar no controle do excesso de escoamento superficial e de cheias urbanas. Observa-se, porém, que estas tecnologias ainda apresentam um alto valor de mercado e que, por isso, hoje, apenas as maiores rendas teriam condições de adquiri-las.

O viés fortemente econômico deste artigo indica, por exemplo, que deve haver a viabilização de incentivos fiscais e econômicos por parte do Poder Público aos fabricantes (pela isenção ou redução de alguns tributos, por exemplo) e aos consumidores (regulamentação do IPTU Verde, dentre outros), visando um maior alcance e disseminação destes sistemas. Paralelamente, deve haver soluções para financiamento a juros menores que os praticados no mercado.

Sabe-se, porém, que outras medidas também podem viabilizar a prática, como por exemplo, uma regulamentação que auxilie profissionais das áreas de saneamento e construção civil na elaboração de projetos, execução, operação e manutenção destes tipos de sistemas dentro das edificações, estimulando as boas práticas e reduzindo os riscos potenciais à saúde pública. O desconhecimento sobre o potencial econômico e sobre o retorno financeiro também representam uma barreira de mercado à adoção de medidas de conservação da água como esta apresentada no artigo, havendo, portanto, a necessidade de divulgação destas informações. 
Neste momento, a Resolução da Adasa deve, dentre outros pontos, ser capaz de atender o interesse público, o mercado, a concessionária e o próprio consumidor e, principalmente, dirimir possíveis conflitos que porventura possam emergir destas práticas em geral.

Em resumo, é perfeitamente possível que o DF consiga aumentar sua autonomia e resiliência hídrica pelo aproveitamento da água pluvial em residências, desde que as medidas identificadas sejam disponibilizadas à população, que se sentirá estimulada a investir.

\section{Referências}

ABNT/CE-002: 146.004 - Comissão de Estudo de Conservação de Água em Edificações. São Paulo: Associação Brasileira de Normas Técnicas, 2018

ABNT/CE-002: 146.004 - Comissão de Estudo de Conservação de Água em Edificações. São Paulo: Associação Brasileira de Normas Técnicas, 2018.

ADASA. Audiência Pública no 06/2018. Brasília: Agência de Águas, Energia e Saneamento Básico do Distrito Federal. Brasília: ADASA, 2018. Disponível em: http://www.adasa.df.gov.br/audienciaspublicas/audiencias-em-andamento/audiencias-publicas/audiencias-em-andamento/1198-audienciapublica-n-06-2018. Acesso em: 11 de julho de 2018.

ADASA. Resolução no 03/2019: Brasília: Agência de Águas, Energia e Saneamento Básico do Distrito Federal. Brasília: ADASA, 2018. Disponível em: http://www.adasa.df.gov.br/images/storage/legislacao/Res_ADASA/Resolucao_n_03_2019.pdf. Acesso em: 23 de março de 2019.

ANA (Brasil). Conjuntura dos recursos hídricos no Brasil 2017: relatório pleno. Agência Nacional de Águas. Brasília: ANA, 2017.

BRASIL. Lei Federal no 13. 501/2017, de 31 de outubro de 2017. Brasília: Governo Federal, 2017.

CBCS. Aspectos da Construção Sustentável no Brasil e Promoção de Políticas Públicas. São Paulo: Conselho Brasileiro de Construção Sustentável, 2014.

CODEPLAN. Pesquisa Distrital por Amostra de Domicílios. Brasília: Companhia de Planejamento do Distrito Federal, 2016.

GDF. Lei Distrital no 4181, de 21 de julho de 2008. Brasília: Governo do Distrito Federal, 2008.

GDF. Lei Distrital no 5.890, de 12 de junho de 2017. Brasília: Governo do Distrito Federal, 2017.

GDF. Lei Complementar Distrital n 929, de 28 de julho de 2017. Brasília: Governo do Distrito Federal. 2017.

GDF. Lei Distrital n 5965, de 16 de agosto de 2017. Brasília: Governo do Distrito Federal. 2017.

GDF. Lei Distrital $n^{\circ}$ 6065, de 11 de janeiro de 2018. Brasília: Governo do Distrito Federal. 2017.

GDF. Plano Distrital de Saneamento Básico. Brasília: Brasília. Governo do Distrito Federal, 2017. No prelo. Disponível em: http://www.planodesaneamentodf.com.br/download-de-documentos.

Acesso em: 20 de julho de 2018.

SANT'ANA, D. R.; MEDEIROS, L. Aproveitamento de águas pluviais e reúso de águas cinzas em edificações: princípios de políticas tarifárias baseados em uma análise de viabilidade técnica, ambiental

e econômica.

Disponível

em: 
Em busca de autonomia e resiliência hídrica no Brasil | Paranoá 23

http://www.adasa.df.gov.br/images/storage/area_de_atuacao/abastecimento_agua_esgotamento_sanit ario/regulacao/reuso_aguas_cinza_aproveitamento_aguas_pluviais/reusodf_1_politicas_tarifarias.pdf. Acesso em 10 de julho de 2018. 